Provided for non-commercial research and educational use only. Not for reproduction or distribution or commercial use.

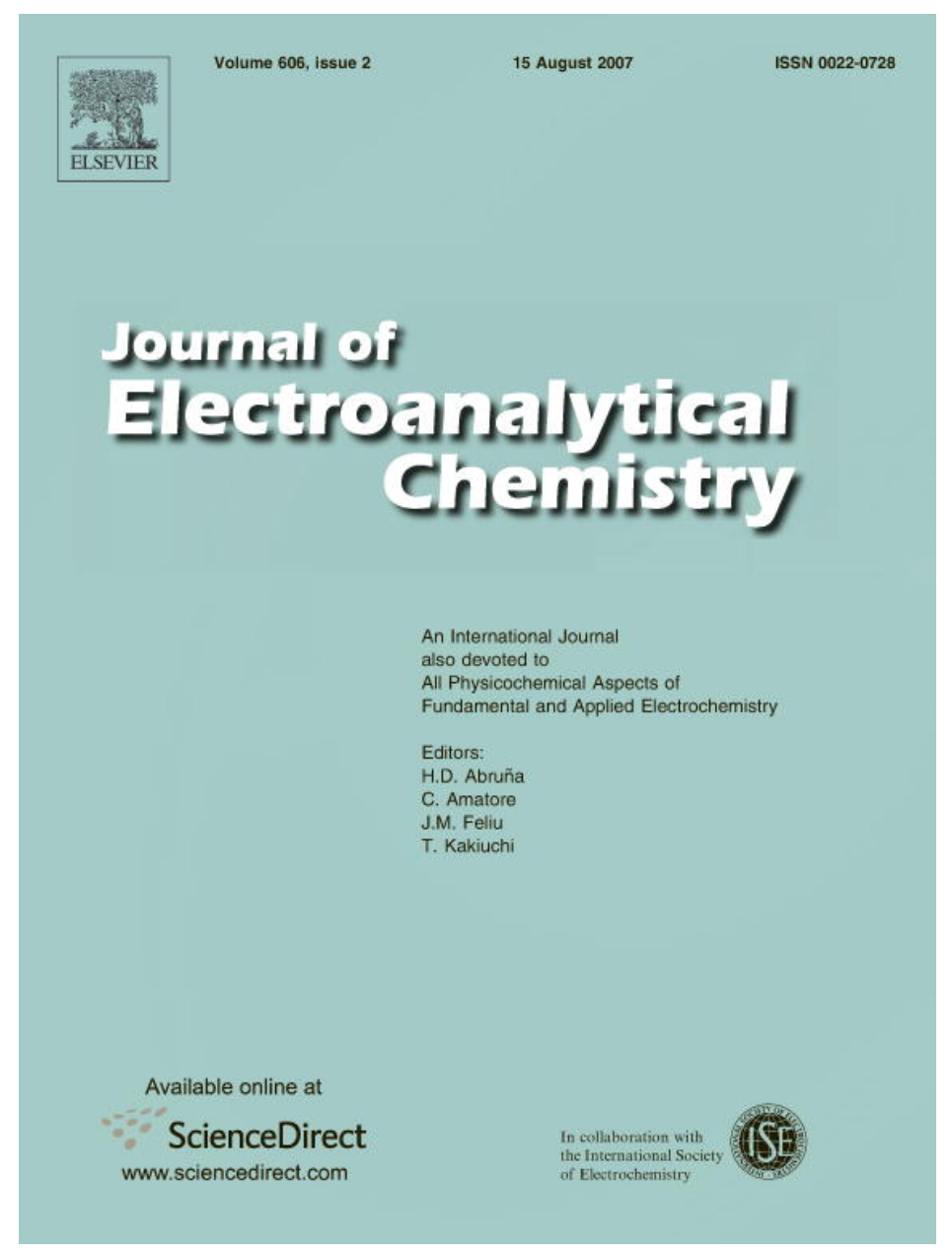

This article was published in an Elsevier journal. The attached copy

is furnished to the author for non-commercial research and education use, including for instruction at the author's institution, sharing with colleagues and providing to institution administration.

Other uses, including reproduction and distribution, or selling or licensing copies, or posting to personal, institutional or third party websites are prohibited.

In most cases authors are permitted to post their version of the article (e.g. in Word or Tex form) to their personal website or institutional repository. Authors requiring further information regarding Elsevier's archiving and manuscript policies are encouraged to visit: 


\title{
The use of microelectrodes with AGNES
}

\author{
César Huidobro a, Encarnació Companys ${ }^{\text {a }}$, Jaume Puy ${ }^{\text {a }}$, Josep Galceran ${ }^{\text {a,*, }}$ \\ Jose Paulo Pinheiro ${ }^{\mathrm{b}}$ \\ a Departament de Quimica, Universitat de Lleida, Rovira Roure 191, 25198 Lleida, Spain \\ ${ }^{\mathrm{b}}$ Centro de Biomedicina Molecular e Estrutural, Departamento de Química, Bioquímica e Farmácia, Faculdade de Ciências e Tecnologia, \\ Universidade do Algarve, Campus de Gambelas, 8005-139 Faro, Portugal
}

Received 3 April 2007; received in revised form 18 May 2007; accepted 4 June 2007

Available online 9 June 2007

\begin{abstract}
Absence of gradients and nernstian equilibrium stripping (AGNES) is a new electroanalytical technique designed to determine free heavy metal ion concentrations in solutions. AGNES had been applied, up to date, with conventional equipment such as the hanging mercury drop electrode (HMDE). Due to their much smaller volume, microelectrodes can reach a given preconcentration factor within a much shorter deposition time, so their use for AGNES has been evaluated in this work. For the particular case of the mercury microelectrode deposited onto an Ir disk (radius around $5 \mu \mathrm{m}$ ), AGNES has been successfully used for speciation purposes in the system $\mathrm{Pb}+\mathrm{PDCA}$ (pyridinedicarboxylic acid). However, due to a relatively large capacitive current, which decays slowly, the limit of quantification for such microelectrodes has only been reduced by one half with respect to that of the HMDE.
\end{abstract}

(C) 2007 Elsevier B.V. All rights reserved.

Keywords: Microelectrode; Speciation; Stripping; AGNES

\section{Introduction}

Absence of gradients and nernstian equilibrium stripping (AGNES) is a recently electroanalytical technique [1] specifically designed for the determination of free metal ion concentration of amalgamating elements. One essential feature is the need to reach a special situation (called "target" for convenience) by the end of the deposition (or first stage), so that key parameters of this technique, such as deposition time and deposition potential have to be selected judiciously, especially if one desires to achieve the target within the minimum deposition time (or to reach the lowest limit of detection for a given deposition time). In previous works [2,3], we have developed different strategies to reduce the deposition time such as the use of a lower gain factor $Y$ (controlled via the deposition poten-

\footnotetext{
${ }^{*}$ Corresponding author. Tel.: +34 973702826.

E-mail address: galceran@quimica.udl.es (J. Galceran).
}

tial) or the use of two potential steps along the deposition stage.

In this work we aim at analyzing the potential of microelectrodes to perform AGNES. Microelectrodes have been gaining importance in trace metal studies [4-7] due to their unique properties, such as a decreased ohmic potential drop, current increase due to enhanced mass transport at the electrode boundary, fast establishment of a steady state signal and increased signal to noise ratio, which originates in the changing conditions of the mass transport from the bulk towards the electrode as compared with a macroelectrode [8]. These characteristics together with the possibility of miniaturization are driving an increasing use of microelectrodes for in situ measurements $[9,10]$.

According to the theoretical analysis developed for AGNES, a reduction of the volume of the amalgam can help in achieving the target conditions sooner, because much less amount of metal is needed to be deposited in order to reach a given preconcentration. The spherical (or hemispherical) geometry of the electrodes is helpful as 
this shape corresponds to a large ratio of the accessible area over the volume, and takes advantage of the convergence of the spherical diffusion along the deposition step. So, here we aim at testing the use of reduced drop sizes because if the value of the radius $r_{0}$ is smaller, we will need shorter times to achieve the sought equilibrium. In this implementation we have used well described mercury microelectrodes deposited on Ir discs with radius around $5 \mu \mathrm{m}[4,11]$.

\section{Theory}

The basic principles of AGNES have been described elsewhere [1]. Briefly, we recall that the first stage is the deposition (or preconcentration) stage whose aim is to reach a situation of no concentration gradient at either side of the electrode surface, while keeping a fixed ratio (given by the gain or preconcentration factor $Y$, determined by the applied potential $E_{1}$ ) of the electroactive couple concentrations due the Nernstian equilibrium

$Y=\frac{c_{\mathrm{M}^{0}}}{c_{\mathrm{M}}}=\exp \left[-\frac{n F}{R T}\left(E_{1}-E^{0 \prime}\right)\right]$

where $E_{0}^{\prime}$ stands for the formal standard potential of the redox couple of the metal M, $F$ is the Faraday, $R$ the gas constant, $T$ the temperature, and $c_{\mathrm{M}^{0}}$ and $c_{\mathrm{M}}$ refer to the final homogeneous (flat) concentration value inside the mercury electrode and the bulk free metal concentration, respectively. The duration of the deposition stage is denoted $t_{1}$.

The second stage is a stripping phase designed to measure the final concentration $c_{\mathrm{M}^{0}}$. In the current implementation, we apply a reoxidation potential $\left(E_{2}\right)$ under diffusion limited conditions and, at a certain time $t_{2}$, we measure the current from which, through subtraction of the blank current, we obtain the faradaic current. As the faradaic current is linearly related with $c_{\mathrm{M}^{0}}$ (due to the linear nature of the diffusion equation for $c_{\mathrm{M}^{0}}$ inside the mercury electrode), and, as $c_{\mathrm{M}^{0}}$ is just $Y c_{\mathrm{M}}$, the faradaic current is proportional to the free metal ion concentration

$I=h c_{\mathrm{M}}$

We can extend a simple model [1], which consists in starting from a balance of the number of the arriving moles (by diffusion) with the change in concentration inside the amalgam. With a variable $m$ we can embrace the case of spherical electrode $(m=4)$ and hemispherical electrode $(m=2)$ :

$\frac{d}{\mathrm{~d} t}\left(\frac{m}{3} \pi r_{0}^{3} c_{\mathrm{M}^{0}}\right)=\frac{D_{\mathrm{M}}\left(c_{\mathrm{M}}-\frac{c_{\mathrm{M}^{0}}}{Y}\right)}{\delta} m \pi r_{0}^{2}$

where $D_{\mathrm{M}}$ is the diffusion coefficient in solution and $\delta$ is the effective diffusion layer which is $r_{0}$ for microelectrodes [6] but depends on the stirring conditions for the HMDE. The r.h.s. stands for diffusion under steady state conditions. This means that this model neglects transient effects (which can be a more drastic approximation for the HMDE) and considers that steady state is instantaneously achieved. By integration of previous Eq. (3) one finds

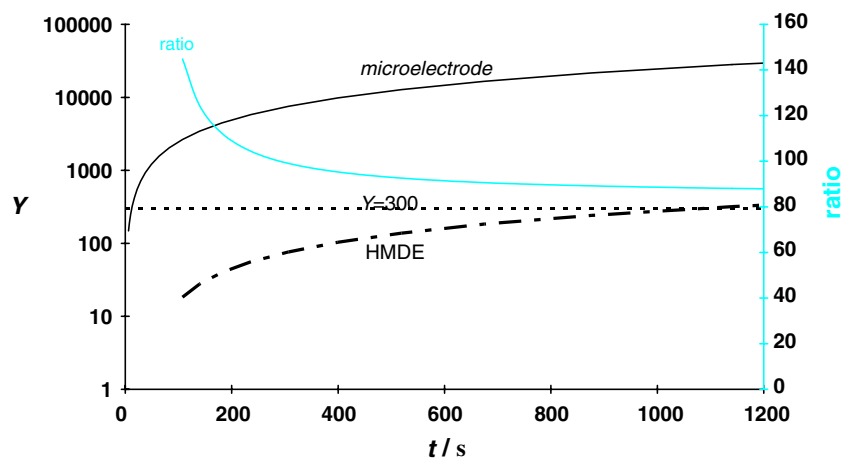

Fig. 1. Gain ( $Y$ ) (up to $99 \%$, i.e. fixing $1-c_{\mathrm{M}^{0}} / Y_{c_{\mathrm{M}}}=0.01$ in Eq. (4)) attained with a microelectrode (black continuous line) and with a standard HMDE (dotted-dashed line) in terms of the deposition time. The horizontal dashed line indicates a fixed gain $Y=300$. The grey continuous line corresponds to the ratio of gains $Y_{\text {micro }} / Y_{\mathrm{HMDE}}$ (referred to the right vertical axis). Parameters of the simulation: $D_{\mathrm{M}}=9.45 \times 10^{-10} \mathrm{~m}^{-1} \mathrm{~s}[18]$; HMDE: $r_{0}=1.41 \times 10^{-4} \mathrm{~m}, \delta=1.5 \times 10^{-5} \mathrm{~m}$ and $t_{\mathrm{w}}=50 \mathrm{~s}$; microelectrode: $\delta=r_{0}=5 \times 10^{-6} \mathrm{~m}$ and $t_{\mathrm{w}}=0$.

$1-\frac{c_{\mathrm{M}^{0}}}{Y c_{\mathrm{M}}}=\exp \left(-\frac{3 D_{\mathrm{M}}}{Y r_{0}}\left(\frac{t_{1}-t_{\mathrm{w}}}{\delta}+\frac{t_{\mathrm{w}}}{r_{0}}\right)\right)$

We have applied this equation in Fig. 1 to compute the time (in the abscissas) needed to reach $99 \%$ of any requested gain (in ordinates) for the smallest drop of a conventional $\operatorname{HMDE}\left(r_{0}=141 \mu \mathrm{m}\right.$ for the Metrohm stand) and for the $\mathrm{Hg}-\mathrm{Ir}$ microelectrode $\left(r_{0}=5 \mu \mathrm{m}\right)$. In both cases larger gains require larger deposition times. One can see that, for a fixed gain, the microelectrode reaches the vicinity of the prescribed gain faster than the HMDE. The horizontal dashed line indicates a typical (working with HMDE) gain of $Y=300$, from which one sees that HMDE would require around $1000 \mathrm{~s}$ whilst the microelectrode would require just some $12 \mathrm{~s}$. The plot also includes (referred to the right vertical axis) the ratio of gains $Y_{\text {micro }} /$ $Y_{\text {HMDE }}$ at each time. For standard times (say $400 \mathrm{~s}$ ) the expected ratio of gains is around 95 . We conclude, then, that the microelectrode is expected to reach much higher gains than HMDE within a given deposition time.

\section{Materials and methods}

\subsection{Reagents}

All solutions were prepared in ultrapure water (Milli-Q plus 185 System, Millipore). Lead standard solutions were prepared by adequate dilution from a Merck $1000 \mathrm{mg} \mathrm{L}^{-1}$ stock solution. Potassium nitrate was used as the inert supporting electrolyte and prepared from solid $\mathrm{KNO}_{3}$ (Fluka, Trace Select). Pyridinedicarboxylic acid (Fluka, p.a.) was used as complexing agent. A stock solution of MES buffer (2-N-morpholino)ethanesulphonic acid was prepared from the solid (Sigma, SigmaUltra), and the $\mathrm{pH}$ was adjusted to $\mathrm{pH} 6.1$ with $\mathrm{KOH}$. Mercuric acetate, $\mathrm{KSCN}$ and potassium hexacianoferrate (all Fluka, p.a.) and $\mathrm{HClO}_{4}$ (J.T. Baker, Baker Instra-Analyzed Reagent) were also used for the 
preparation and characterisation of the microelectrode. Purified water-saturated nitrogen $\mathrm{N}_{2}(50)$ was used for deaeration and blanketing of solutions.

\subsection{Instrumentation}

Voltammetric measurements were carried out with an Eco Chemie Autolab PGSTAT30 potentiostat attached to a Metrohm 663 VA Stand and to a computer by means of the GPES (Eco Chemie) software package. The working electrode was either a Metrohm multimode mercury drop electrode (with the smallest drop of the stand, $r_{0}=1.41 \times$ $10^{-4} \mathrm{~m}$ ) to which we refer to as macroelectrode, or a mercury-coated iridium microelectrode (Idronaut, Italy, $r_{0}=5 \times 10^{-6} \mathrm{~m}$ ). The auxiliary electrode was a glassy carbon electrode and the reference electrode was $\mathrm{Ag} / \mathrm{AgCl} /$ $3 \mathrm{~mol} \mathrm{~L}^{-1} \mathrm{KCl}$, encased in a $0.1 \mathrm{~mol} \mathrm{~L}^{-1} \mathrm{KNO}_{3}$ jacket.

In all experiments with the HMDE, stirring was accomplished with the PTFE tip stirrer of the Metrohm 663 VA Stand, which is screwed onto the driving axis. The rotation rate is set on the 663 VA Stand and it was fixed at $1500 \mathrm{rpm}$. A glass cell provided by Metrohm was used in all measurements, which were performed at room temperature.

When working with the microelectrode, the specified setup suffered dramatic interferences. To avoid these interferences, a home-made Faraday cage was specially designed to shield the cell, the electrodes and all the wires. A simple box covered with aluminium foil was used for the cell and the electrodes. This box was attached to a wide aluminium tube, which enclosed all the electrical wires.

\subsection{Preparation and characterization of the microelectrode}

The working microelectrode consisted of a hemispherical mercury droplet electrodeposited onto an iridium disk microelectrode. The iridium surface was initially prepared by successively wet grinding with $10 \mu \mathrm{m}$ and $5 \mu \mathrm{m}$ silicon carbide paper (Struers pads 2400 and 4000, respectively), followed by final polishing with $1 \mu \mathrm{m}$ diamond paste (Struers, KITON) on a DP-Mol polishing cloth (Struers, DEKOL) lubricated with DP-Lubricant Blue (Struers, DEPT1). All polishing steps were performed using an automated polishing system (see [4]).

Mercury was plated onto the Ir substrate at $-0.40 \mathrm{~V}$ in a solution of $5 \times 10^{-3} \mathrm{M}$ mercuric acetate and $0.1 \mathrm{M} \mathrm{HClO}_{4}$ solution. The deposition was halted when the charge reached $Q=6 \mu \mathrm{C}$ [4], which is consistent with the formation of a hemispherical drop of $\mathrm{Hg}$ having $r_{0}$ around $6 \mu \mathrm{m}$ on top of the Ir disk. Limiting currents recorded with potassium hexacianoferrate confirmed this radius for the analyzed $\mathrm{Hg}$ drops. However, we stress that the actual size (and shape) of the electrode is not essential in the validity of AGNES experimental results, as long as the same electrode is used both in the calibration and in the measurement (as done in this work) and provided the target is achieved by the end of the first stage (i.e. using safe deposition times).

Following deposition of the mercury droplet, the microelectrode was rinsed with distilled water and transferred to the solution to be analysed. A fresh mercury electrode surface was prepared daily. The mercury was removed at the end of each set of experiments by scanning the potential linearly from -0.30 to $0.30 \mathrm{~V}$ at $5 \mathrm{mV} \mathrm{s}^{-1}$ in a $1 \mathrm{M} \mathrm{KSCN}$ degassed solution [4]. In this way we could check that practically all the $\mathrm{Hg}$ initially deposited was present until the end of the experiments.

\subsection{AGNES procedures}

For a typical experiment with microelectrode, Fig. 2 shows the potential program of the simplest AGNES experiment $(E$, referred to the right axis, versus $t$ ) depicted as a thick solid line in the plot, together with the measured current $(I$, referred to the left axis versus $t$ ). A strategy (called " 2 pulses" or " $2 \mathrm{P}$ ") developed to reduce the time of the experiment [2] (and applied here with HMDE) consists in splitting the first deposition stage into two substages, with diffusion limited conditions for the deposition along the first substage.
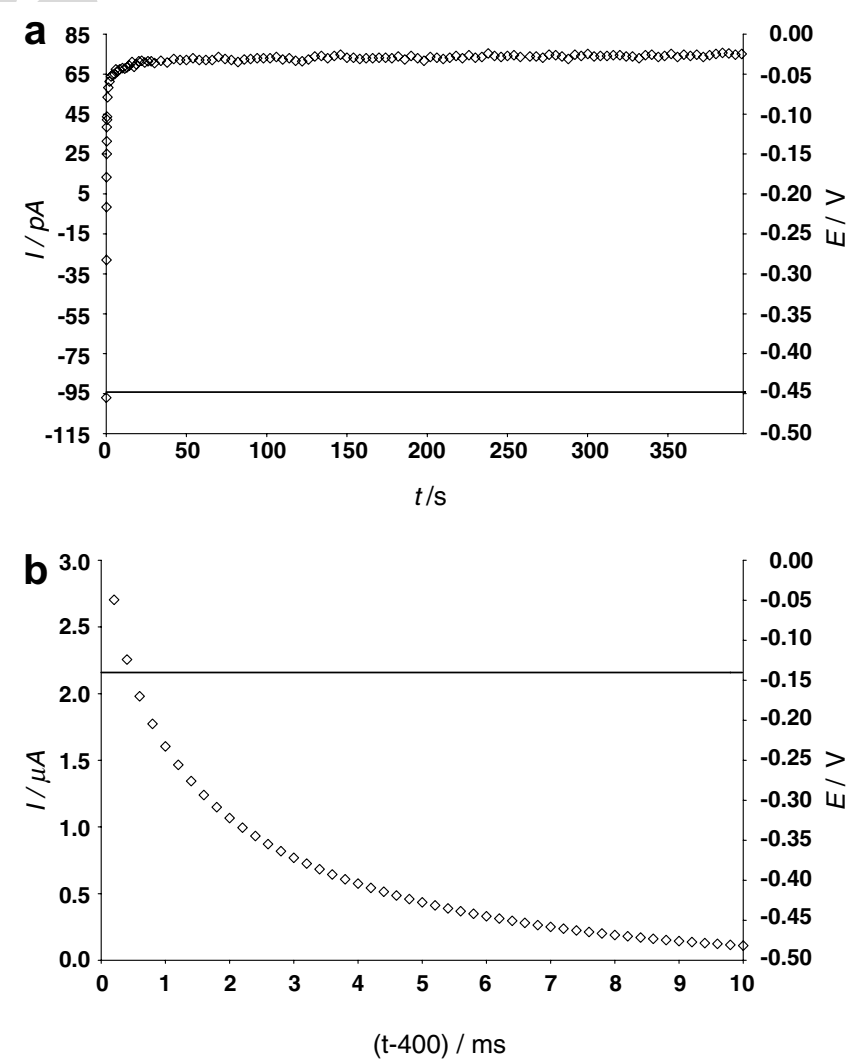

Fig. 2. Plot of the measured currents (open diamonds, referred to left vertical axis) and the applied potential program (thick solid line, referred to the right vertical axis) against time of the experiment. $\left[\mathrm{Pb}^{2+}\right]_{\text {total }}=10^{-5} \mathrm{M}$. Panel (a) First stage with deposition potential $Y=5000$; panel (b) the first points of the stripping (or second) stage with $Y_{2}=5 \times 10^{-7}$. 


\section{Results and discussion}

\subsection{Selection of the optimum $t_{2}$}

The subtraction of the blank current is required to obtain the faradaic current. The first developed blank [1], which could be called the "synthetic" blank, consists in applying essentially the same potential program to the same solution, but without the targeted metal ion. In this work we have used the "shifted" blank introduced in Ref. [3], which mostly corresponds to the capacitive current. Indeed, in the shifted blank, the deposition potential $E_{1, \mathrm{sb}}$ corresponds to a very low gain $\left(Y_{\mathrm{sb}}=0.01\right)$ and we apply a $E_{2, \mathrm{sb}}$ keeping the same potential jump $(\Delta E=$ $E_{2, \mathrm{sb}}-E_{1, \mathrm{sb}}$ ) than with the ordinary or "main" (i.e. when we apply the typical gains, say $Y=5000$ ) measurements, $\Delta E=E_{2}-E_{1}$. Despite some authors [12] have reported low capacitive currents for solid band electrodes, we have, rather, found relatively large charging currents with our $\mathrm{Hg}-\mathrm{Ir}$ microelectrodes (even with the bare Ir basal electrode and no $\mathrm{Hg}$ deposited on it). For instance, for $\left[\mathrm{Pb}^{2+}\right]=10^{-5} \mathrm{M}$ with $t_{1}=400 \mathrm{~s}$, at $t_{2}=1 \mathrm{~ms}$ we have measured a shifted blank current of $5.33 \times 10^{-9} \mathrm{~A}$ and a main current of $4.5 \times 10^{-7} \mathrm{~A}$ when we used $Y=500$, while for a $\operatorname{HMDE}\left(t_{2}=0.25 \mathrm{~s}\right)$ typical blank values are around $2.5 \times 10^{-9} \mathrm{~A}$ in the case of the shifted blank and main current of $1.44 \times 10^{-6} \mathrm{~A}$ working with $Y=50$. Moreover, the capacitive current of our $\mathrm{Ir}-\mathrm{Hg}$ microelectrodes decays more slowly than the faradaic one, as seen in Fig 3, where we have normalised the blank currents (mostly capacitive, see upper lines) and the faradaic current obtained by subtraction of the shifted blank to the main measurements (see lower lines) so that they have a unity value at $1 \mathrm{~ms}$. To avoid effects from the residual oxygen current present along the experiments, all currents in this plot are referred

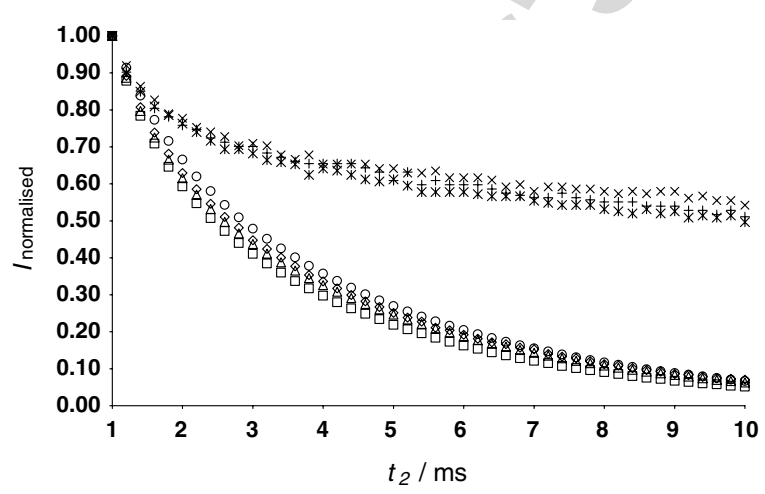

Fig. 3. Decay of normalised stripping currents along the second stage of AGNES. Upper curves (markers $\times, *$ and + ): shifted blanks (mostly capacitive) current. The normalization of this current is: $\left(I_{\mathrm{b}}-I_{\mathrm{b}, \infty}\right) /$ $\left(I_{\mathrm{b}}(1 \mathrm{~ms})-I_{\mathrm{b}, \infty}\right)$. Lower curves: faradaic currents due to $\mathrm{Pb}^{0}$ reoxidation. The normalization of this faradaic current is: $\left(\left(I-I_{\infty}\right)-\left(I_{\mathrm{b}}-I_{\mathrm{b}, \infty}\right)\right) /$ $\left[\left(I(1 \mathrm{~ms})-I_{\infty}\right)-\left(I_{\mathrm{b}}(1 \mathrm{~ms})-I_{\mathrm{b}, \infty}\right)\right]$. Markers: $\diamond,\left[\mathrm{Pb}^{2+}\right]_{\text {total }}=4.17 \times 10^{-7} \mathrm{M}$; $\square, \quad\left[\mathrm{Pb}^{2+}\right]_{\text {total }}=1.02 \times 10^{-6} \mathrm{M} ; \quad \triangle, \quad\left[\mathrm{Pb}^{2+}\right]_{\text {total }}=4.07 \times 10^{-6} \mathrm{M} ; \quad \bigcirc$, $\left[\mathrm{Pb}^{2+}\right]_{\text {total }}=1.01 \times 10^{-5} \mathrm{M} ; Y=5000 . t_{1}=400 \mathrm{~s}$. The normalisations of the currents imply that they all cross the unity value at $1 \mathrm{~ms}$. to the residual (final) current value achieved $\left(I_{\infty}\right)$ at very large stripping time (usually $21 \mathrm{~s}$ ). Notice how, for different metal concentrations, all normalised faradaic currents (lower curves) collapse, indicating the linearity between faradaic current and concentration (see Eq. (2)) regardless of the measurement time.

We have performed some experiments to verify whether the blank current is affected by oxygen concentration in the solution or it is mainly capacitive. We recorded several (synthetic and shifted) blanks along the purging process which, as expected, resulted in residual currents $I_{\infty}$ (i.e. at a very long time after the application of the stripping pulse) decreasing when the concentration of oxygen in solution was reduced. This residual current $I_{\infty}$ can be, thus, considered as a measure of the $\mathrm{O}_{2}$ present in the sample and was taken as abscissas in Fig. 4. This figure shows that the level of oxygen has little impact on the total current of the blanks at the short time of the measurement (e.g. $1 \mathrm{~ms}$ ). A similar irrelevance of oxygen in microelectrodes was already described when using fast electrochemical techniques [13].

As seen in Fig. 5 the ratio of blank current over total current goes through a minimum around $1 \mathrm{~ms}$, so we have chosen this time as the standard $t_{2}$ for this work. This value of $1 \mathrm{~ms}$ is also the one leading to the minimum Limit of Quantification (see Section 4.3) because it is a compromise between a sufficiently short time (so that $h$ is large) and a sufficiently long time (so that the capacitative current is low).

\subsection{Calibration}

Firstly, we performed a calibration of our setup and conditions with solutions containing known concentrations of $\mathrm{Pb}(\mathrm{II})$ and background electrolyte. Within the 1 pulse strategy (i.e. the simplest potential program consisting of only one deposition potential [1], see Fig. 2), we applied different values of deposition gains ( $Y=500,1000,2000$, 5000 and 10,000) and in each of them we measured the

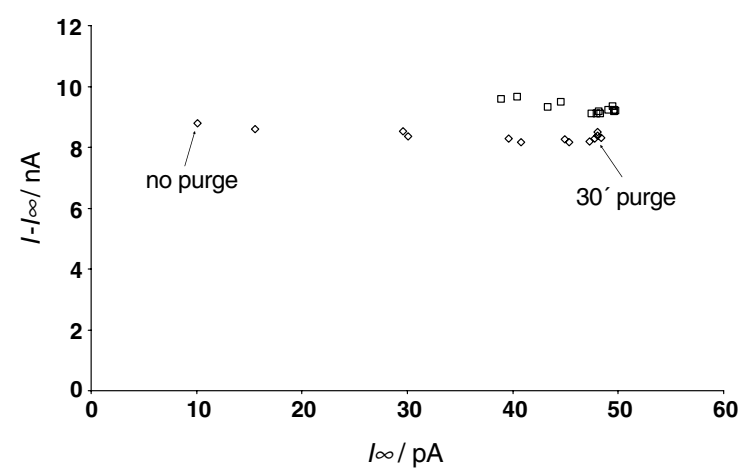

Fig. 4. Plot of the blank current (once its residual current $I_{\infty}$ has been subtracted) versus the residual current $I_{\infty}$. Each point represents a measurement performed in a $\mathrm{KNO}_{3} \quad 0.1 \mathrm{M}$ solution after a certain time during the degassing process with pure $\mathrm{N}_{2}$. $\square$, shifted blank. $Y_{1}=0.01$, $t_{1}=50 \mathrm{~s} . \diamond$, synthetic blank. $Y_{1}=100, t_{1}=50 \mathrm{~s}$. 


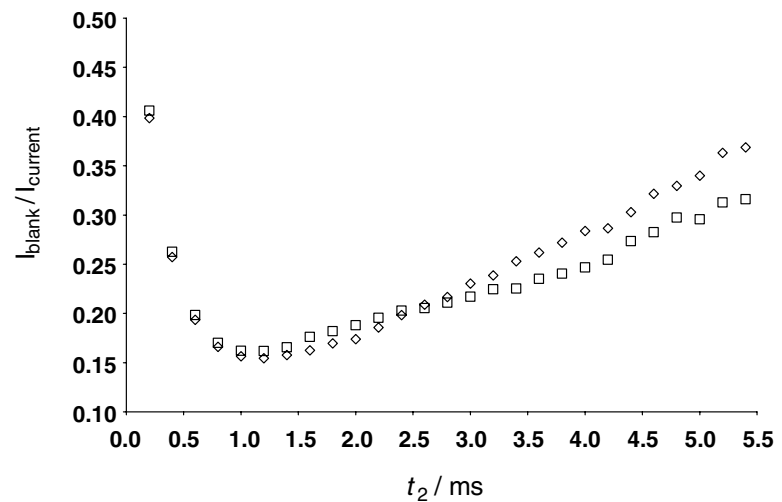

Fig. 5. Ratio of blank current over total current along the stripping step (second stage) for a concentration of $\left[\mathrm{Pb}^{2+}\right]=2.03 \times 10^{-6} \mathrm{M}$ and $Y_{1}=500$ showing the convenience of choosing $t_{2}=1 \mathrm{~ms}$. The two markers stand for two replicates.

currents for different values of the deposition time $t_{1}$. In Fig. 6, we can see that -for a fixed $Y$-the current initially increases with increasing deposition time up to a practically constant $I$-value, which indicates us the minimum time needed for accepting that AGNES conditions have been achieved. For example, using $Y=5000$, we achieve AGNES conditions with the microelectrode in around $400 \mathrm{~s}$. This deposition time is clearly less than the one required by the $\operatorname{HMDE}\left(r_{0}=1.41 \times 10^{-6} \mathrm{~m}\right)$ to reach the same $Y$, which can be estimated, from extrapolation of values reported in experiments previously published [2]: $Y=50$ usually requires $t_{1}-t_{\mathrm{w}}=350 \mathrm{~s}$, so $Y=5000$, given the proportionality between $Y$ and $t_{1}-t_{\mathrm{w}}$ seen in Eq. (4), would require $t_{1}-t_{\mathrm{w}}=35,000 \mathrm{~s}$ to which we have to add the standard resting time $t_{\mathrm{w}}=50 \mathrm{~s}$, to finally reach $35,050 \mathrm{~s}$. This reduction (from $35,050 \mathrm{~s}$ to $400 \mathrm{~s}$ ) is consistent with the theoretical reduction factor of around 95 (see Section 2). As expected, we also see in Fig. 6 that higher gains $Y$ require longer deposition times and that there is a proportionality between the achieved current and the applied $Y$ (given that $h$ is directly proportional to $Y$ ).

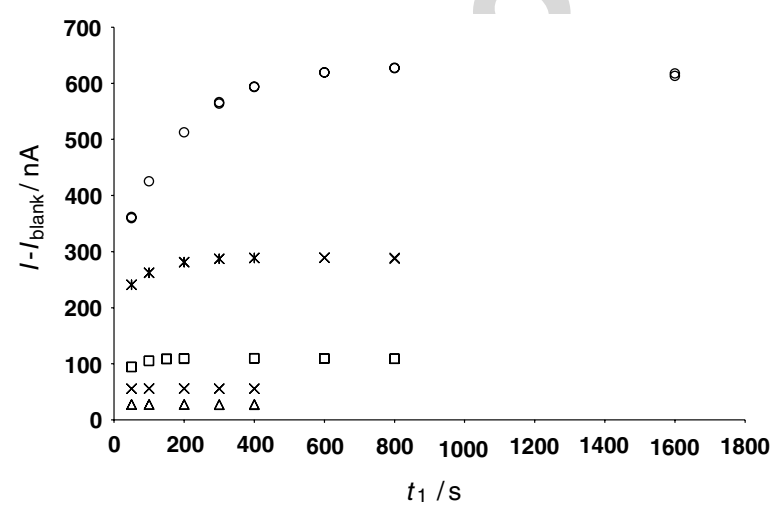

Fig. 6. Plot of the faradaic current at $t_{2}=1 \mathrm{~ms}$ versus deposition time $\left(t_{1}\right)$. Markers: $\triangle, Y_{1}=500 ; \times, Y_{1}=1000 ; \square, Y_{1}=2000 ; *, Y_{1}=5000 ; \bigcirc$, $Y_{1}=10,000 . \Delta E=0.2958 \mathrm{~V}$ was fixed in all experiments by changing $Y_{2}$. Solution: $\left[\mathrm{Pb}^{2+}\right]_{\text {total }}=2.03 \times 10^{-6} \mathrm{M} ;[\mathrm{MES}]=10^{-2} \mathrm{M} ;\left[\mathrm{KNO}_{3}\right]=0.1 \mathrm{M}$; pH 6.1. "Shifted" blank applied with $Y_{1}=0.01$.
In order to check the proportionality (prescribed by Eq. (2)) between measured current and free metal concentration, in Fig. 7 we have plotted $I$ vs. $c_{M}$ at two different $Y$-values (2000 and 5000). The slope of each straight line yields the value of the proportionality factor, $h$, which lies around $h \approx 0.071$ for $Y=2000$ and $h \approx 0.187$ for $Y=5000$. As predicted by Eq. (A.7) in Ref. [1] and as previously observed in Fig. 6, there is a direct proportionality between $h$ and $Y$ (i.e. $0.187 / 0.071 \approx 5000 / 2000$ ).

\subsection{The limit of quantification}

With the values reported in previous sections we can perform an estimation of the LOQ (Limit of Quantification) obtained with our microelectrode. We computed this value from six shifted blank replicates corresponding to the calibration experiment using

$\operatorname{LOQ}(\mathrm{M})=\frac{\bar{I}_{\mathrm{b}}+10 s_{n-1}}{h}$

where $\bar{I}_{\mathrm{b}}$ and $s_{n-1}$ are the mean and the standard deviation of the blank replicates, respectively [14].

In Table 1, we compare the LOQ obtained with the macroelectrode and the microelectrode for the same deposition time $\left(t_{1}=400 \mathrm{~s}\right)$. These results show that working with the microelectrode we can reduce the limit of quantification almost by a factor of two.

\subsection{System Pb-PDCA (2,6-Pyridinedicarboxylic acid)}

We move now to assess the speciation capabilities of AGNES with the well-known system $\mathrm{Pb}-\mathrm{PDCA}$. We have performed a titration by adding different concentrations of PDCA into a solution that contains a total $\mathrm{Pb}(\mathrm{II})$ concentration of $1.82 \times 10^{-6} \mathrm{M}$ and a MES concentration of $10^{-2} \mathrm{M}$ to fix the value of the $\mathrm{pH}$ to 6.1 .

We used the two-pulse (2P) strategy for the experiments with HMDE, where the deposition time is split into a diffusion limited substage during $t_{1, \mathrm{a}}$ seconds and an

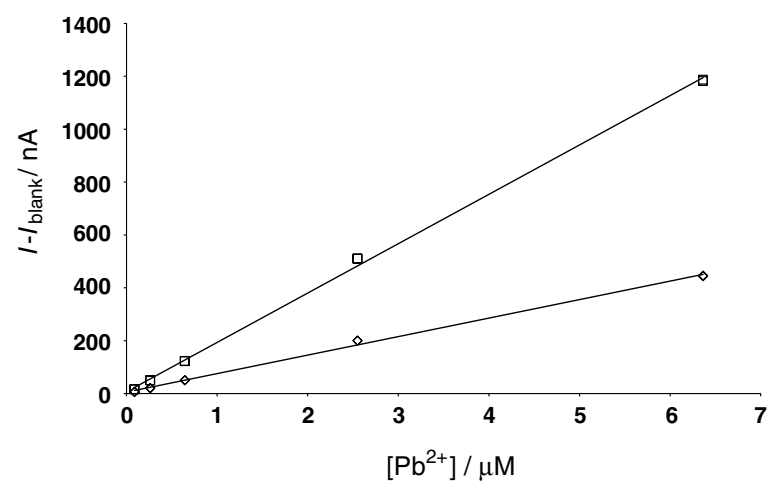

Fig. 7. Plot of the intensity current versus free concentrations of $\mathrm{Pb}$ (computed with MINTEQ) allowing the calibration of AGNES. $\diamond$, $Y_{1}=2000 ; t_{1}=200 \mathrm{~s} ;$ slope $=0.071 ; R^{2}=0.998 ; \square, Y_{1}=5000 ; t_{1}=400 \mathrm{~s}$; slope $=0.187 ; R^{2}=0.9991 . \Delta E=0.2958 \mathrm{~V}$ fixed in both cases by changing $Y_{2}$ as required. 
Table 1

Estimation of the limit of quantification with the macroelectrode and the microelectrode at the same deposition time (fixed $t_{1}=400 \mathrm{~s}$ ) applying 1 pulse strategy

\begin{tabular}{lrllll}
\hline & $Y$ & $\begin{array}{l}h / \mathrm{A} \\
\mathrm{M}^{-1}\end{array}$ & $\bar{I}_{\mathrm{b}} / \mathrm{A}$ & $s_{n-1} / \mathrm{A}$ & LOQ/M \\
& & & & \\
\hline HMDE & 50 & 0.130 & $2.76 \times 10^{-9}$ & $7.16 \times 10^{-10}$ & $7.92 \times 10^{-8}$ \\
Microelectrode & 5000 & 0.187 & $5.33 \times 10^{-9}$ & $3.63 \times 10^{-10}$ & $4.79 \times 10^{-8}$ \\
\hline
\end{tabular}

equilibration (at the desired gain) substage during $t_{1, \mathrm{~b}}$ seconds. The gain $Y$ was selected so that the blank was practically negligible in front of the measured current, while the characteristic times $t_{1, \mathrm{a}}$ and $t_{1, \mathrm{~b}}$ were found by a bisection method [15], consisting in seeking that there is no significant variation in the measured current when the equilibration time $\left(t_{1, \mathrm{~b}}\right)$ is enlarged.

Experiments with the microelectrode followed the simplest strategy of one potential (1P), whose potential program is depicted in Fig. 2. $Y$ values where selected so that the required deposition times could be taken $t_{1}=$ $200 \mathrm{~s}$, leading to a main measurement current around 3-5 times that of the blank. We were able to increase $Y$ with increasing concentration of ligand because of the contribution of the complex [2].

Fig. 8 gathers the different free concentrations of $\mathrm{Pb}$ measured with the microelectrode. These results satisfactorily agree with theoretical expected values computed with MEDUSA [16] (using $K_{1}^{\mathrm{Pb}}=5.01 \times 10^{8} \mathrm{M}^{-1}$ and $\beta_{2}^{\mathrm{Pb}}=$ $3.98 \times 10^{11} \mathrm{M}^{-2}$ and $K_{1}^{\mathrm{H}}=4.79 \times 10^{4} \mathrm{M}^{-1}$ and $\beta_{2}^{\mathrm{H}}=$ $6.03 \times 10^{6} \mathrm{M}^{-2}$ [17]) and with the results obtained experimentally using AGNES technique with $\operatorname{HMDE}\left(r_{0}=\right.$ $1.41 \times 10^{-6} \mathrm{~m}$ ) and the strategy of two pulses [2] (i.e. the first stage is split into two substages, with diffusion limited conditions for the deposition along the first one). A slight difference between theoretical and experimental values

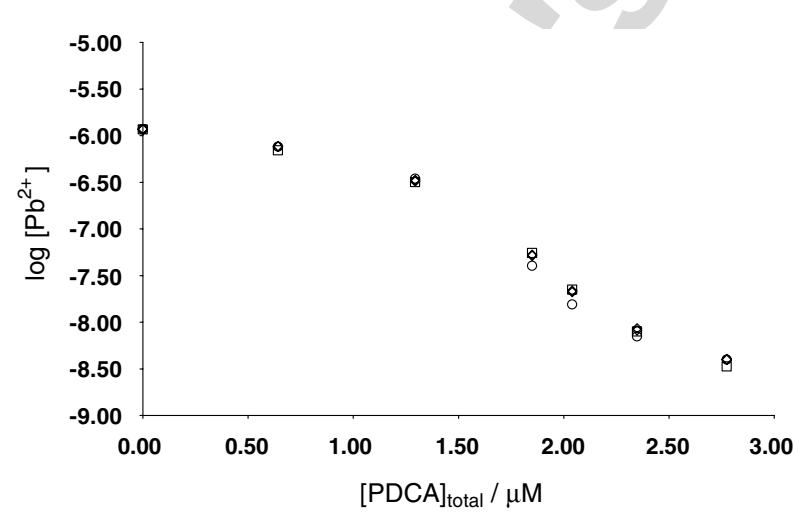

Fig. 8. Speciation measurements of AGNES with microelectrodes. Measured free concentration of $\mathrm{Pb}$ versus total concentration of PDCA. Markers: $\square$, MEDUSA calculations; $\diamond$, AGNES with microelectrode, $t_{1}=200 \mathrm{~s}, Y$ changing from $10^{3}$ when there is no ligand up to $Y=10^{5}$ when the added [PDCA] is $2.77 \times 10^{-6} \mathrm{M}$; $\bigcirc$, AGNES with HMDE. $Y$ changes from $10^{2}$ when there is no ligand up to $Y=10^{4}$ when the added $[\mathrm{PDCA}]$ is $2.77 \times 10^{-6} \mathrm{M}$. In all experiments $\left[\mathrm{Pb}^{2+}\right]_{\text {total }}=1.82 \times 10^{-6} \mathrm{M}$; $\left.[\mathrm{MES}]=10^{-2} \mathrm{M} ; \mathrm{KNO}_{3}\right]=0.1 \mathrm{M} ; \mathrm{pH}$ 6.1. "Shifted" blank applied with $Y=0.01$. appears when the total concentrations of metal and ligand are similar. This fact could be due to uncertainties in the stability constants or in the composition of the solution.

\section{Conclusion}

AGNES had been applied up to now with conventional equipment, such us the Hanging Mercury Drop Electrode (HMDE). The use of microelectrodes, with a much smaller volume, has been evaluated in this work. Experiments performed here confirm their capability to reach a preconcentration factor with shorter times.

For the particular case of a microelectrode of mercury deposited onto an Ir disk the limit of quantification appears to be reduced approximately by a factor of two with respect to the conventional HMDE. A relatively high capacitive current seems to be responsible for not obtaining a larger reduction.

The $\mathrm{Hg}$-Ir microelectrode has been shown to be useful for speciation purposes, since the free lead concentration was successfully measured in the system $\mathrm{Pb}-\mathrm{PDCA}$. The capabilities of performing speciation studies with AGNES using microelectrodes is specially interesting if we keep in mind the possibility to bring them to the field and the possible use of smaller samples, specially in cases where an ISE does not exists $(\mathrm{Zn})$ or is not always very reliable $(\mathrm{Pb})$. Future work, focussed on the reduction of the longer time of preparation and on the increase of the mechanical resistance of the drop is needed to improve the practical application of $\mathrm{Hg}$-Ir microelectrodes with AGNES in the field.

\section{Acknowledgement}

The authors gratefully acknowledge support of this research by "Acción Integrada"/“Acciao Integrada" SpainPortugal HP2004-0066. Financial support by the Spanish Ministry of Education and Science (Projects CTQ200614385 and CTM2006-13583) and from the "Comissionat d'Universitats i Recerca de la Generalitat de Catalunya" is also acknowledged. Acceptance of C. Huidobro for two months in CABE's lab (J. Buffle and M.L. Tercier-Waeber) is also gratefully acknowledged.

\section{References}

[1] J. Galceran, E. Companys, J. Puy, J. Cecília, J.L. Garcés, J. Electroanal. Chem. 566 (2004) 95.

[2] E. Companys, J. Cecília, G. Codina, J. Puy, J. Galceran, J. Electroanal. Chem. 576 (2005) 21.

[3] J. Galceran, C. Huidobro, E. Companys, G. Alberti, Talanta 71 (2007) 1795.

[4] M.L. Tercier, N. Parthasarathy, J. Buffle, Electroanalytical 7 (1995) 55.

[5] C. Belmont, M.L. Tercier, J. Buffle, G.C. Fiaccabrino, M. KoudelkaHep, Anal. Chim. Acta 329 (1996) 203.

[6] M.E. Abdelsalam, G. Denuault, S. Daniele, Anal. Chim. Acta 452 (2002) 65.

[7] X.D. Xie, D. Stueben, Z. Berner, Anal. Lett. 38 (2005) 2281. 
[8] K. Stulik, C. Amatore, K. Holub, V. Marecek, W. Kutner, Pure Appl. Chem. 72 (2000) 1483.

[9] J. Buffle, M.L. Tercier-Waeber, in: J. Buffle, G. Horvai (Eds.), In situ monitoring of aquatic systems, John Wiley, Chichester, UK, 2000, p. 279 (Chapter 9).

[10] J. Buffle, M.L. Tercier-Waeber, TrAC-Trends Anal. Chem. 24 (2005) 172.

[11] H.P. van Leeuwen, R.M. Town, J. Electroanal. Chem. 523 (2002) 16.

[12] K.R. Wehmeyer, M.R. Deakin, R.M. Wightman, Anal. Chem. 57 (1985) 1913.

[13] A.S. Baranski, Anal. Chem. 59 (1987) 662.
[14] D.C. Harris, Quantitative Chemical Analysis, sixth ed., Freeman and Co., New York, 2003.

[15] G. Alberti, R. Biesuz, C. Huidobro, E. Companys, J. Puy, J. Galceran, A comparison between the determination of free $\mathrm{Pb}(\mathrm{II})$ by two techniques: AGNES and Resin Titration. Anal. Chim. Acta, submitted for publication.

[16] Medusa: make equilibrium diagrams using sophisticated algorithms. Windows program. [computer program]. Puigdomenech I. Royal Institute of Technology KTH, Stockholm, Sweden; 2001.

[17] G. Anderegg, Helv. Chim. Acta 43 (1960) 414.

[18] D.R. Lide, CRC Handbook of Chemistry and Physics, 77 ed., CRC Press, Boca Raton, FA, 1996. 